LCRL- 98649

PREPRINT

\title{
FINAL OPTIC PROTECTION OESIGNS FOR ICF CONTAINMENT CHAMBERS
}

\author{
David G. Nilson \\ and \\ John G. Woodworth
}

\section{This paper was prepared for submittal to \\ Eighth Topical Meeting on the \\ Technology of Fusion Energy \\ Salt Lake City, Utah \\ October 9-13, 1988}

August 23, 1988

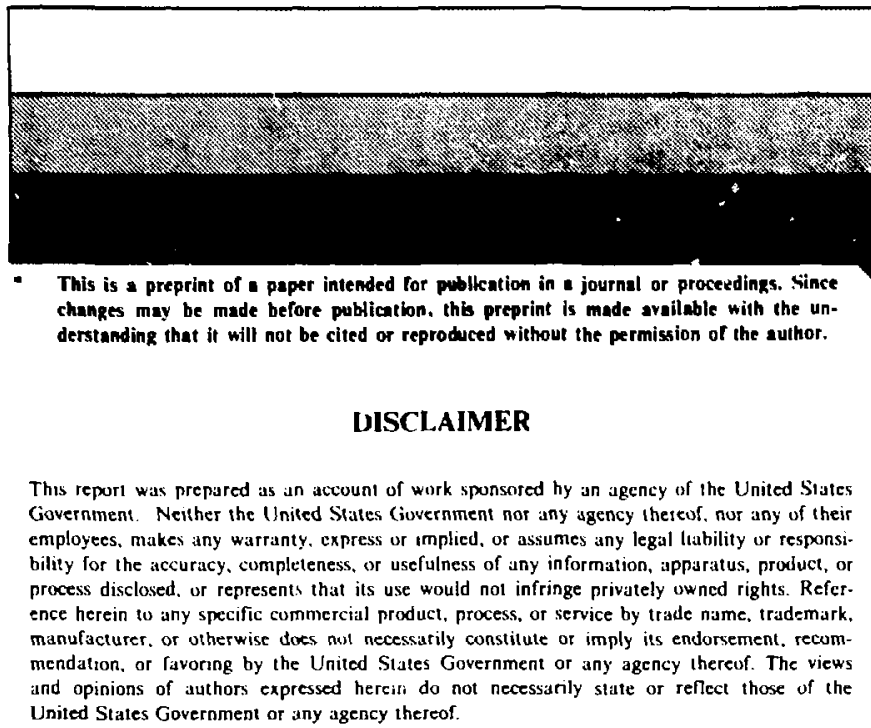

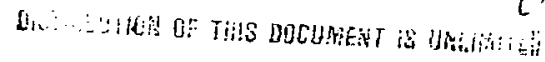




\title{
FINAL OPTIC PROTECTION DESIGNS FOR ICF CONTAINMENT CHAMBERS*
}

\author{
David G. Nilson and John G. Woodworth \\ Lawrence Livermore National Laboratory \\ P. O. Box 5508, Livermore National Laboratory
}

UCRL -98649

DE 89004885

(415) $422-5386$

\begin{abstract}
The output from a laser-driven high-gain ICF target in the laboratory microfusion facility (LMF) target chamber could produce enough $x$-rays, shrapnel, and debris to severely damage the laser's final optics. If the final optics were left unprotected, the replacement and reinstallation costs for each beam would exceed $\$ 40 \mathrm{~K}$. Assuming the laser has 68 beams, the repla zement costs for each shot co uld reach $\$ 2.7 \mathrm{M}$. To avoid these excessive costs, we must design a reliable optics protection system. This requires that we define the hazardous environment to which the optics are exposed.
\end{abstract}

Thegeometrical layout for the 68 beams of the 10 megajoule laser shows the final optics placed at 25 meters from the target (see Fig. 1). The final optic will be a $2-5 \mathrm{~cm}$ thick debris shield (\$40K each) which will be placed in front of a $\$ 200 \mathrm{~K}$ focussing lens. Each of the 68 beams will deliver $150 \mathrm{~kJ}$ of $0.35 \mu \mathrm{m}(3 \omega)$ light and will consist of either $a 4 \times 4$ or $a 2 \times 8$ array of beamlets, with each beamlet aperture having dimensions of $29 \mathrm{~cm} \times 29 \mathrm{~cm}$. This produces a $3 \omega$ energy density at the final optic of $12 \mathrm{~J} / \mathrm{cm}^{2}$ a verage and $225-30 \mathrm{~J} / \mathrm{cm}^{2}$ peak.

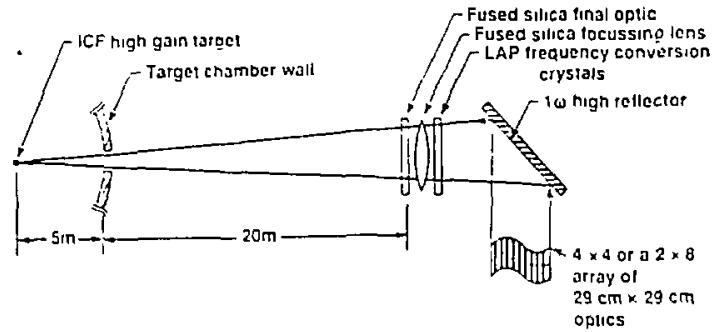

Figure 1. Geometry of final optics for ICF megajoule laser.

\section{ENVIRONMENTAL CONDITIONS}

Assuming a maximum credible output from a high gain shot will produce $1400 \mathrm{M}$ ) of energy, abr.it one third of this energy will be in the form of $x$-rays and debris (high-speed ions), which gives an energy fluence of about $6 \mathrm{~J} / \mathrm{cm}^{2}$ at 25 meters from the target where the final optics are located. This energy flux, which we can represent as a black body $x$-ray spectrum peaking at $1 \mathrm{keV}$ photon energy, is sulficient to produce permanent damage on the front surface of fused silica optics., ${ }^{1,2}$ Additionally, because the peak $x$-ray flux has a short penetration depth and pulsewidth (10 nsec), it causes vaporization to occur on front surfaces of any objects located near the target. This vaporization produces large pressures (shock waves) in the material which could generate back surface spall. The spalled fragments could have extremely high velocities $(\sim 10 \mathrm{~km} / \mathrm{sec})$ which would likely damage the final optics. We have performed calculations which predict the size and velocity of the particles produced from back surface spall. ${ }^{3}$ In the calculations, we placed a target inside of a $25 \mathrm{~cm}$ diameter beryllium sphere (called a Compton Sphere), and exposed the sphere to the $x$-ray fluxes from various target yields. The results show that the inner layers will vaporize and melt at low yields. At high yields, the outer portions of the solid shell will fracture and produce hyper-velocity fragments (see Table 1). The calculations also indicate that the mass of the fragments from the fractured layer will range from $.007 \mathrm{gm}$ to $1.49 \mathrm{gm}$ and could have velocities of up to $4 \mathrm{~km} / \mathrm{sec}$, depending on the target yield. Additional fragmentation calculations are currently underway in which the target neutron flux is accounted for. These are expected to also predict the velocity and mass of vapor, liquid and solid particles generated from objects located near chamber center. By adjusting the geometry and materials of this sphere and other potential debris generators, such as target diagnostic devices, we hope to limit the maximum momentum of any particle to be no greater than $0.02 \mathrm{~kg}-\mathrm{m} / \mathrm{sec}$. This is equivalent to a $1 \mathrm{~mm}$ diameter carbon particle traveling at $10 \mathrm{~km} / \mathrm{sec}$.

An additional hazard that the final optics are exposed to is the unbumed tritium from the target. An estimate of the amount of tritium that could enter a beam tubecan becalculated by assuming that all of the $500 \mathrm{Ci}$ from each target is uniformly distributed throughout the target chamber and beam tube voiumes. This gives each beam tube $2 \mathrm{Ci}$ which should then bc diluted with a gas and pumped to a tritium reservoir. 


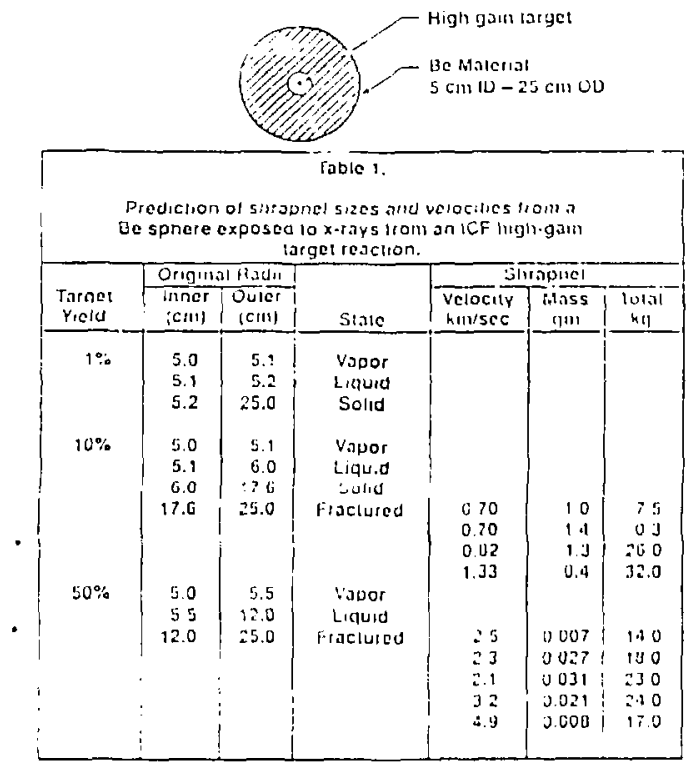

Additionally, there will be a sustained post-shot pressure rise in the chamber and beam tube volumes when they absorb the $450 \mathrm{MJ}$ of energy in $x$-rays and debris released from the target. This pressure rise could be on the order of 1 atmosphere, which is sufficient to cause high loads on the beam tube walls and optics. The remaining $2 / 3$ of the $1400 \mathrm{MJ}$ released by the target will becontained in the large number of neutrons emitted $\left(4 \times 10^{20}\right)$. The total neutron flux from the facility's 500 lifetime high gain shots at 25 meters from the target is $2 \times 10^{15}$ neutrons/ $\mathrm{cm}^{2}$. This neutron flux is the threshold for color center formation in fused silica. The final optics protection equipment (i.z., valves, and cleaning equipment) can be shiclded from the direct neutron flux by placing it behind the chamber wall. However, it could still be activated by the high levels of scattered neutrons. Therefore, we must construct the beam tubes and optics protection devices from low activating materials such as carbon, plastics, or aluminum. Small amounts of higher activating materials can be used if they are shielded properly.

\section{PROTECTION SOLUTIONS}

Of the various environmental hazards exposed to the final optics, the high-speed shrapnel is the most difficult to deal with. The primary design requirement is that the protection solution stop $1 \mathrm{~mm}$ diameter carbon particles which are traveling at speeds up to $10 \mathrm{~km} / \mathrm{sec}$. This shrapnel could appear in the beam tubes for as long as $100 \mathrm{msec}$ after the target shot has gone off, which requires that the protection device remain in the aperture for this time period.

There have been numerous calculations and tests performed to determine the thickness and type of protection plate materials required to stop high-speed particles. Empirical formulae derived from the results of penetration tests show that the required plate thickness varies linearly with the projectile momentum/unit arca." These formulae are only valid for particles travelling below the sound speed of the plate material; however, they still provide a good thickness estimate for alumi- num plates stopping $10 \mathrm{~km} / \mathrm{sec}$ particles. Using these formulae, we calculated that a $1 \mathrm{~cm}$ thick aluminum plate is required to stop a $1 \mathrm{~mm}$ diameter carbon particle traveling at $10 \mathrm{~km} / \mathrm{sec}$. Typically, when a particle with this velocity strikes a plate, it will be vaporized in the first few millimeters of plate material. The vaporization causes the formation of a large shock wave which expands towards the back end of the protection plate. Provided that the plate has sufficient thickness, the shock wave will expand and attenuate so that it will not cause spallation on the back surface. The $1 \mathrm{~cm}$ thick aluminum plate provides a factor of safety of 1.5 to ensure protection from back surface spall from the $1 \mathrm{~mm}$ diameter particles.

A possible method to quickly insert a $1 \mathrm{~cm}$ thick aluminum plate into the beam tube aperture is to accelerate two plates toward each other with pressurized gas (sce Fig. 2). This "guillotise" type valve would be placed just outside the chamber wall which is currently located 5 meters from the target. If the valve is in this Incation, and the fastest shrapnel veloctly is 10 $\mathrm{km} / \mathrm{sec}$, the plate must close the aperture in $0.5 \mathrm{msec}$. Given a beam port aperture at the chamber wall of $12 \mathrm{~cm} \times 55 \mathrm{~cm}$, the plate must be traveling at a constant velocity of $120 \mathrm{~m} /$ secacross the aperture for it to close before the shrapnel flies by. The time at which the plate enters the aperture must be very precisely controlled. If it arrives too early, it will block the laser beam, and if it is too late the shrapnel will get by and destroy the optics.

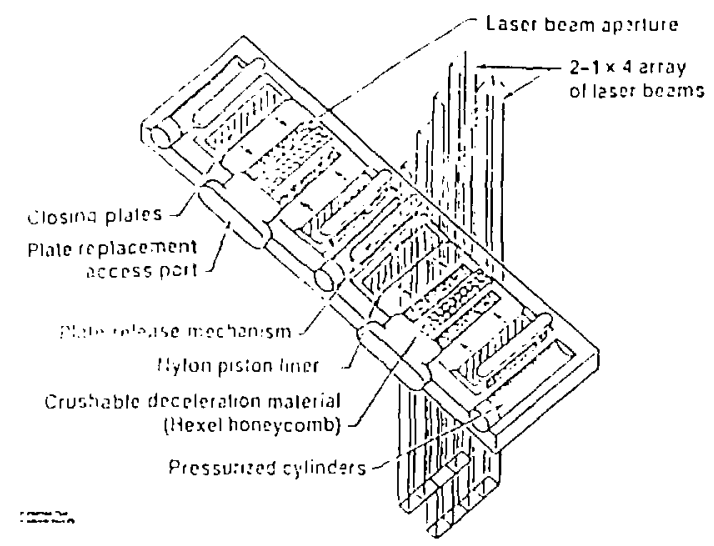

Figure 2. Fast valve for shrapnel protection.

The dual-plate guillotine valve design currently under consideration has two advantages. First, the large impulsive forces from the acceleration and deceleration of the two plates will be equal and opposite. This reduces the concem that vibration from the valve will disrupt the laser alignment prior to the shot. Secondly, the required plate velocity is reduced by a factor of two because each plate must cover only half of the beam tube aperture in the same $0.5 \mathrm{msec}$ time interval. A $6 \mathrm{~cm}$ wide strip of crushable material will be placed at the center of the aperture to provide a stopping cushion for the plates. The predicted deceleration forces in the plate should create stresses that are well below the yield stress of the material. 
In order to achieve a $120 \mathrm{~m} / \mathrm{sec}$ closing velocity, the aluminum plate must be accelerated with approximately $4000 \mathrm{psi}$ gas, depending on the specific valve design. Two existing methods of achieving this short-duration, high pressure gas pulse are to either expose the plate to a pressurized gas reservoir or to an explosive charge. Because of the ease of operation and the lack of burn residue, we have chosen to accelerate the plates with a pressurized reservoir as shown in Fig. 2 . This type of design is commonly used in high pressure gas guns. Because the plate sees full gas pressure before it is moved, there is no pressure pulse risetime to degrade the temporal response of the valve. The accuracy of the response time will be determined primarily by the temporal accuracy of the plate release mechanism.

A drawback of the guillotine valve design is that if the aluminum plates are damaged by shrapnel, they will have to be replaced. It is difficult to estimate how many plates will need replacement after each shot due to the uncertainties in the shrapnel directionality. However, if one assumes that the shrapnel generated from a snuall diagnostic is emitted isotropically, there will be enough shrapnel produced to provide several particles per beam line. This would require that all of the plates be replaced after each shot. Even if a protection plate is not damaged by shrapnel, each valve must have its crushed deceleration material replaced after each shot. Clearly, using this insertable plate method to provide shrapnel protection will require a considerable amount of operational effort. It is important to realize the real penalty of shrapnel protection. Assuming each valve system can be serviced in one hour, and the replacement costs for the aluminum plates and crushable material are approximately $\$ 100 /$ beamline, it is conceivable that the shrapnel protection operational costs for a single slot would be under $\$ 14,000$. This would then amount to only a small portion of the LMFs projected operational costs of $\$ 200 \mathrm{~K}-\$ 300 \mathrm{~K} / \mathrm{shot}$.

Other shrapnel protection solutions using rapidly inserted material have been proposed and subsequently rejected for various reasons. Some of these alternative systems included multiple liquid jets, magnetically driven flyer plates, and rotating plates and nywheels (see Table 2). The liquid jets and fly-

\begin{tabular}{|c|c|c|c|}
\hline - & Shrapneı P & $\begin{array}{l}\text { le } 2 . \\
\text { ction Concepts }\end{array}$ & \\
\hline Concept & $\begin{array}{l}\text { Tilning } \\
\text { accuracy }\end{array}$ & $\begin{array}{l}\text { Post-shot } \\
\text { serviceabihy }\end{array}$ & $\begin{array}{l}\text { Feasibility } \\
\text { using current } \\
\text { lechnology }\end{array}$ \\
\hline Guillolıne vaivo & Unknown & Four & Excellent \\
\hline Ratatıng valve & Excellent & Poor & Good \\
\hline Liquid valve & Unknown & Excellem & Good \\
\hline Flyw heel & Excellent & Poor & Fair \\
\hline $\begin{array}{l}\text { Replaceable } \\
3 \omega \text { mirrors }\end{array}$ & Excellent & Poor & Poor \\
\hline $\begin{array}{l}\text { Replaceable } \\
\text { debris smieids }\end{array}$ & Excellent & Poor & Poor \\
\hline $\begin{array}{l}\text { Magneuc flyer } \\
\text { ploies }\end{array}$ & Good & Poor & Unknown \\
\hline
\end{tabular}

wheels were rejected because the aperture is only protected for the brief period that the material is in the aperture. The rotating plates and magnetically driven flyer plates are still under consideration, but the stresses invoived in stopping the plates once they are in the aperture are extremely high.

More elegant solutions to the shrapnel problem which use optical techniques have been investigated, but they will require large technological advances to be viable solutions. One of these methods is to develop a high reflecting $3 \omega$ coating and use replaceable mirrors as the final optics (see Fig. 3 ). This would allow the expensive focussing optics and frequency conversion crystals to be placed behind a shield where they would be well away from the environmental hazards. Unfortunately, the current damage threshold for $3 \omega$ HR coatings is typically only $10-15 \mathrm{~J} / \mathrm{cm}^{2}$ which is $2-3$ times less than the required damage threshold of $225-30 \mathrm{~J} / \mathrm{cm}^{2} .5$ With a strong $\mathrm{re}-$ search effort, damage thresholds of $25.30 \mathrm{~J} / \mathrm{cm}^{2}$ might he attainable. A possible method to avoid this threshold problem would be to use a blow away coating that would tamp the reflective surface, thus allowing the light to be reflected off its surface before it can damage more significantly. This might be possible because of the short 50 nsec laser pulse that we intend to use

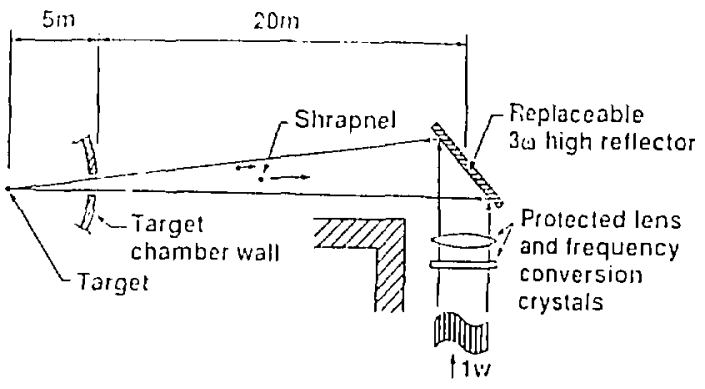

Figure 3. Geemetry for a replaceable $3 w$ high reflector shrapnel protection system.

A drawback to he replaceable mirror method is that an inexpensive mirror su'sstrate must be developed. If each mirror were destroyed after every shot, it would have to be replaced for $\$ 500$ /beamline per shot for it to compete with the guillotine valve protection method. It is a formidable task to develop a 2 meter $r^{2}$ coated mirror substrate for $\$ 500 /$ unit, especially when current projected costs for mirrors exceed $\$ 40 \mathrm{~K} /$ unit.

Another possible shrapnel protection method is to develop an inexpensive replaciable debris shield that is placed between the final optic and the target. This optical material would have to be $2-4 \mathrm{~cm}$ thick to stop the high speed particles. It must also transmit $25.30 \mathrm{~J} / \mathrm{cm}^{2}$ of $3 \omega$ light and be flat to within a few microns. This might be achieved by pouring a $3 \omega$ transmitting liquid between two flat surfaces and then cooling the liquid to form a solid. The phase replicating surface plates would be removed just prior to the shot, and then be AR coated or placed at Brewsters angle to avoid the surface reflection losses. Significant phase replication development is required for this method to compete with the $\$ 500$ /beamline cosi level of the guillotine valve. 


\section{X-RAY AND ION PROTECTION}

As previously stated, the final optics will be subjected to large $x$-ray and high-speed ion fluences which begin to arrive at the optic as soon as $\mathbf{8 3} \mathbf{n s e c}$ after the laser fires. The curnent design for providing this protection is to inject argon gas into each beam hube between the final optic and the target. By injecting enough argon into the beam tube to achieve a 12 meter long volume of gas at a pressure of 2 torr, the soft $x$-ray flux will

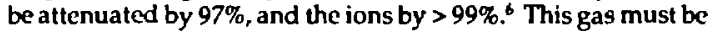
injected just before the laser passes through the beam tube, and done quickly enough so that the gas does not have time to migrate to the center of the chamber where it could be ionized by the focused laser light or condense on a cryogenic target. However, if the gas does not have enough time to disperse evenly throughout the beam tube, it will not provide uniform protection from the $x$-rays. If too much gas is injected, the laser team could te distorted and produce an inadequate focal spot at the target.

Several methods of providing final optic $x$-ray protection with a high density gas have been investigated at LANL and TRW. The most promising of these methods calls for xenon gas to be injected into the beam tube through a fast valve. The injection valve is located on the side of the beam tube near the chamber wall and is opened just before the laser is fired. The gas then rushes out of a reservoir, through a nozzle, and toward the final optic. We propose using a similar fast valve injection design, but instead of using only a nozzic to create the proper gas density, we would add a porous plate (see Fig. 4). If only a nozzle is used to disperse the gas, we believe there is a good chance that large shock waves would be introduced which could form large gas density gradients. There may not be enough time for these density gradients to dissipate before the laser beam passes through them. These gradients could then distort the beam and produce a poor focal spot. By adding a porous plate, the gas would be forced through a number of "small nozzles", which would form much smaller density gradients. These smaller gradients should dampen out more quickly and reduce the effect on beam quality. Additionally, we would use argon instead of xenon gas because it is less expensive.

Current computational methods used to predict turbulent flow fields of injected gas produce marginal results at best. The most accurate way to predict the existing flow fields and their effects on laser propagation is to perform a scaled test of the injection system. We are currently building a scaled gas injection experiment which will allow us to determine three important parameters of our system (see Fig. 4). First, we must determine that the proper temporal profile of the pressure pulse in the beam tube can be established. This can be achieved by placing fast response impedance switches near the porous injection plate and at the exit end of the beam tube. These switches can accurately measure the initial injection time and arrival time of the gas. By comparing these signals with the pressure rise in the cha mber and the opening signal to the injection valve, we can determine the temporal jitter of the injection system. Secondly, we must show that the gas density profile in the beam tube is uniform enough to sufficiently attenuate the $x$ rays. An excellent method for measuring the density profile per unit area is to use beam deflection spectroscopy through the beam tube. Finally, the focal spot distortion from gas density gradients must be determined by focusing a laser through the gas and into a pinhole. The resulting beam distortion can be determined by comparing the amount of light that passes through the pinhole before and after the gas has been injected.

Four valves can injecl - $100 \mathrm{gms}$ ol Argon in - 10-20 msec

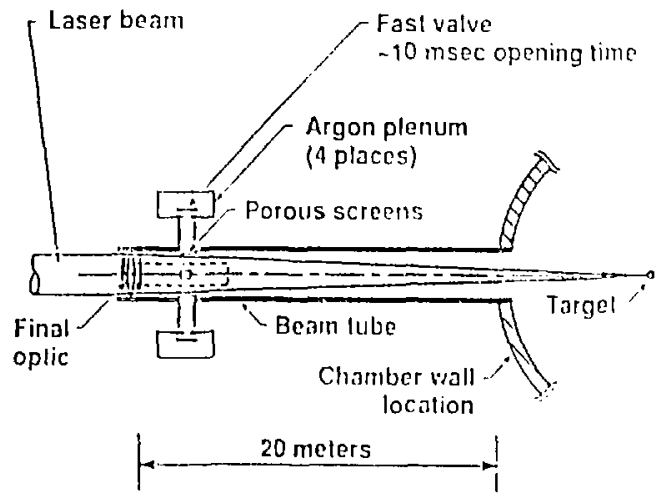

Figure 4. Apparatus to test argon injection system.

\section{SUMMARY}

We have described the hostile environment exposed to the final optics when the maximum credible yield of $1400 \mathrm{M}$ ) is produced inside the LMF chamber. As much as $450 \mathrm{MJ}$ of soft $x$-rays and debris could be emitted from the target which could generate high-speed shrapnel and excessive soft $x$-ray and ion fluxes $\left(6 \mathrm{~J} / \mathrm{cm}^{2}\right)$ at the final optics location. We propose using a guillotine valve consisting of rapidly injected aluminum plates for shrapnel protection. Other protection methods using optical techniques such as replaceable debris shield sor mirrors are being considered, but they will require large technological advances. We propose achieving $x$-ray protection by injecting argon gas in front of the final optics just prior to the shot. A scaled experiment is underway to confirm the gas injection concept.

\section{ACKNOWLEDGMENTS}

We wish to thank the following people for their strong contributions to this work: Neil Frank, Sam Rodriguez, John Pitts, Dennis Slaughter, Bill Comfort, John Clay, Mike Tobin, Max Tabak, Pete Mohr, Al Edge, Dale Schauer, and Bob Harrach.

\footnotetext{
"Work performed under the auspices of the U. S. Department of Energy by the Lawrence Livermore National Laboratory under contract number W-7405-ENG-48.
} 


\section{REFERENCES}

1. C.D. ORTH, "Improved Understanding of First Wall Vaporization-Condensation in Inertial Confinement Fusion Reactors", Seventh Topical Meeting on the Technology of Fusion Energy, Reno, Nevada, 1986

2. L.WEBSTER, Kaman Sciences Corporation, Priv. Comm., (1988)

3. L. WEBSTER and P. SNOW, Kaman Sciences Corporation, Priv. Comm., (1988)

4. Lawrence Livermore National Labboratory, ME Design Safety Standards, M-012, Rev. 6, Pg 4-7, (1986)

5. M. C. STAGGS and F. RAINER, "Damuge Thresholo' for Fused Silica, Plastics, and KDP Crystals, Mensured with 0.6 ns and 355-nm Pulses", Boulder Damage Symposium., 1983, p. 84

6. M. TABAK, Lawrence Livermore National Laboratory, Priv. Comm., (1988)

7. V. KULCARNY, D. MCGREGOR, J. SCHWARTZ, and R.A. BRIONES, "Pulsed Acrodynamic Windows for Fusion Lasers," TRW final report pg 3,1-22, (1981)

8. J. C. MURPHY and L.C. A AMODT, J. Appl. Phys. $\$ 14580$ (1980) 